\title{
Intimate Partner Violence Among Adolescents: What Is Being Done?
}

\author{
Asha Layne \\ Howard University, Washington D.C., USA
}

\begin{abstract}
Literature on domestic violence/IPV (intimate partner violence) prevention among adolescents has focused their attention on behavioral and emotional patterns of abuse and the predictors associated with these observed patterns. Though important, very little research investigating the role of prevention and the rate of IPV have been applied to the adolescent population. Using mixed method research design, this paper examined the preventive measures available for vulnerable victims of domestic violence in an East coast metropolitan area. Results from this analysis illustrated the need for better measures to locate IPV adolescent victims and to provide services tailored specifically for adolescent victims. Implications for prevention and intervention are discussed.
\end{abstract}

Keywords: intimate partner violence, prevention, adolescents

\section{Introduction}

The notoriety of IPV (intimate partner violence) has raised great public concern in recent years as more serious cases are becoming headline news. IPV has become an adult and adolescent issue, especially with the increased exposure of violence among teenagers in relationships. In recent years, studies have focused their attention on dating violence among teens, because of its ability to lead to IPV among adults. In a study on dating violence victimization among students in grades 7 to 12 during 1994-1995, the 18-month prevalence of victimization from physical and psychological dating violence was estimated at 20\% (Halpern, 2001). Among adult victims of rape, physical violence, and/or stalking by an intimate partner, $22 \%$ of women and $15 \%$ of men first experienced some form of partner violence between 11 and 17 years of age (Centers for Disease Control and Prevention, Factsheet, 2012). In a study by the Centers for Disease Control, five risk behaviors were found: unhealthy dieting behaviors, attempted suicide, sexual intercourse, episodic heavy drinking, and physical fighting, among high school victims who were exposed to dating violence. To identify, data from the 2003 Youth Risk Behavior Survey data indicated that $8.9 \%$ (8.9\% of males and $8.8 \%$ of females) among 14,945 students reported physical dating violence victimization during the 12 months preceding the survey and that students reporting personal dating violence victimization were more likely to engage in four of the five risk behaviors: sexual intercourse, attempted suicide, episodic heavy drinking, and physical fighting (Centers for Disease Control and Prevention (MMWR Weekly 5/19/06)).

How adolescents, especially women, are directly affected by abusive dating (or co-habiting) relationships explains their vulnerability to abuse, the meanings of such experiences, and their subsequent recovery processes (Reynolds \& Sheperd, 2011, p. 315). Children exposed to dating violence or IPV are exposed to many risks. 
Studies have shown that exposure to dating violence as an adolescent can be a precursor to IPV victimization in adulthood. An estimated 5.3 million IPV incidents occur each year, resulting in approximately 2 million injuries and 1,300 deaths (Centers for Disease Control and Prevention, 2003). Sleutal reviewed qualities studies of adult women that showed marked effects of partner abuse on identity/self-image, as well as loss of agency, perceived future, and trust in relationships (Sleutal, 1998; Reynolds \& Sheperd, 2011, p. 316).

Even though the problem of teen dating violence has been widely discussed, there has not been an effective method to locate and serve members of this population. Little research has focused their attention on adolescent population due to the low numbers of adolescents filing for protective or peace orders through the court system. This paper seeks to examine services available to vulnerable victims of intimate partner violence in a metropolitan area.

\section{Theories}

Theories on intimate partner violence are multi-dimensional. Like the definition for "abuse" and "intimate partner violence", the theories explaining this phenomenon have also been changed to include several factors. Like any type of violence, not all violence is the same thus not all victims exposed to IPV have the same experiences or background. In carrying this idea, researchers have also identified several types of IPV. The three types are: (1) violence enacted in the service of taking general control over one's partner (intimate terrorism); (2) violence utilized in response to intimate terrorism (violent resistance); and (3) violence that is not embedded in a general pattern of power and control but is a function of the escalation of a specific conflict or series of conflicts (situational couple violence) (Johnson, 2005, p. 1127). In his study, Johnson explains how gender influences the type of abuse seen in IPV. In our society, gender has served as an indicator regarding authority and power which has been carried into personal relations. Giving this history, researchers have found that intimate partner violence was heavily male perpetrated. For example, direct evidence comes from Johnson's finding that $97 \%$ of the intimate terrorism in a 1970s Pittsburgh sample was male perpetrated, compared with $56 \%$ of situational couple violence (Johnson, 2005, p. 1128). Another indicator of the relevance of gender is the relationship of intimate partner violence to traditional gender attitudes and misogyny (Johnson, 2005, p. 1128).

The general attitudes intimate partner violence has examined the power and control model. Some analysts have demonstrated that men who hold patriarchal views are more likely to abuse their female partners, especially through the use of "coercive control" tactics aimed at isolating women from other resources or sources of social support (Brownridge, 2002; MacMillan \& Gartner, 1999; Michalski, 2005, p. 615). Such theoretical reasoning has also been used to explain intimate partner violence at a societal level and historical patterns of violence against women in general (Jiwani, 2000; Sanday, 1981; Michalski, 2005, p. 615). Anchoring these beliefs is the feminist theory of domestic violence. The feminist perspective sees the root cause of domestic violence as the outcome of gender socialization especially within socialized roles. Society has long held women as being non-violent or "submissive" and men as being aggressive or "manly". However, feminist theorists have acknowledged that women can also be violent in their relationships with men which have been seen in situational couple violence.

Measuring theories of conflict and violence between partners in constructed scales of measurements have transformed the way domestic violence is identified. The Conflict Tactics Scales, which consists of two versions - CTS 1 and CTS 2, are the most widely used for identifying domestic violence (Strauss, 2007, p. 190). 
The CTS 1 scale is used to measure violence against a partner in a dating or marital relationship and CTS 2 scale measures victimization and perpetration of three main tactics often used in conflicts between partners: physical assault, psychological aggression, and negotiation; and scales to measure injury and sexual coercion of and by a partner (Strauss, 2007, p. 190). The development of the CTS scales has its theoretical basis in sociology's conflict theory. According to this theoretical perspective, conflict, though sometimes destructive, brings about change, and without conflict change is not produced, thus conflict is inevitable especially among human interaction. What is harmful is not the conflict itself, but the use of coercion, including force and violence, as a tactic for resolving conflicts which can be categorized into two areas: conflict of interest and conflict management (Strauss, 2007, p. 190).

Scales have been used to measure the severity of violence against victims. The SVAWS (Severity of Violence Against Women Scales) is a 46-item questionnaire designed to measure two major dimensions: behaviors that threaten physical violence and actual physical violence (Marshall, 1992; Gist et al., 2001, p. 640). This scale is important because it examines physical aggression in both forms: the act itself and physical aggression that is verbally expressed. Studies have included stalking as a form of violent behavior that falls under harassment, though this is debatable, the act of stalking cannot be ignored in measuring domestic violence. Studies have used the SVS (Stalking Victimization Survey), a 17-item questionnaire, to document the frequency and type of stalking by the intimate partner perpetrator (Gist et al., 2001, p. 640).

Other scales are used to measure the psychological state of abused women. PMWI (the Psychological Maltreatment of Women Inventory) is a 58-item test designed to measure the extent and nature of abuse toward women in a relationship, which is given to women who have survived abuse. Not to exclude men, the version for male victims includes identical behaviors but reverses the pronouns and direction of abuse (retrieved from www.ncbi.nlm.nih.gov). Another scale used to measure IPV is the danger assessment scale. This scale is used because of the several risk factors that have been associated with homicides (murders) of both batterers and battered women in research conducted after the murders have taken place (retrieved from www.ncbi.nlm.nih.gov). Other research-designed scales have been used specifically by researchers to gain insight into family abuse in both victim and perpetrator backgrounds. For example, Hanson and Wallace-Capretta designed a family history questionnaire which was constructed specifically for their study as a brief measure of abuse in the family of origin. The measure contained four subscales addressing the following relationships: treatment by mother, treatment by father, mother's treatment of father, and father's treatment of mother (Public Safety Canada).

\section{Methodology}

To locate victims of IPV, researchers have utilized data from intervention services. These services are: court/police, community, and hospital services. In these descriptive qualitative studies, researchers have conducted surveys of past victims by locating them through court/police documents or hospital documented domestic violence cases. This method has proven to be problematic for several reasons. For one, victims of IPV do not always file orders for protection from their abusers because of fear, financial reasons, or embarrassment. Also, attrition has been problematic among IPV victims especially when victims are repeatedly asked to recount traumatizing events over the period of investigation and court hearings. Lastly, these methods have continuously yielded solutions for mainly the adult population thus excluding younger member of abuse. Below are the following most used methods to measure domestic violence studies: 
(1) Qualitative assessments;

(2) Longitudinal studies;

(3) Secondary analysis.

This paper examines the preventive measures available for domestic violence in Baltimore City, Maryland to measure the effectiveness it has on adolescents of domestic violence. The method of analysis for this study is broken into two waves: analysis of secondary data and analysis of primary data. The use of online quantitative data allowed the author to obtain aggregate data for Baltimore City gathered over a longitudinal period of 12 months as seen in Table 1 and Table 2. Like with any research methods, the use of secondary data has its limitations. Some critics have argued that quantitative data is "data-driven" and lacks any depth or interpretation behind the numbers. As a result, the author has used surveys to promote the qualitative interpretive aspect of this study. Surveys involve the collection of information from individuals and organizations by the use of structured or semi-structured questionnaires or interviews (Remler \& Van Ryzin, 2011, p. 212). A series of semi-structured interviews were employed in this study to attain knowledge of IPV victims in Baltimore City and to assess whether or not domestic violence programs were effective in addressing the adolescent population.

The state of Maryland, more specifically Baltimore City, Maryland is used in this paper. A descriptive overview of Baltimore City is given in Table 1. Baltimore City was selected for several reasons. It is the largest city in the state of Maryland; it has the largest volume of cases which allows one to obtain a substantial number of cases under specific crime offenses (see Table 2); and it is easily identifiable under the Maryland court system data being identified as "Baltimore City" and not a township under a Maryland county.

\section{Protective/Peace Orders}

The motivating rationale for protective orders is, by definition, to reduce the risk of harm resulting from intimate partner violence (Faragher et al., 2006, p. 177). Since the first and mainly used preventive measure against IPV is law enforcement, this area needs to be examined regarding its effectiveness. One main challenge regarding IPV is the issue of underreporting, especially among adolescents. According to Black and Weisz (2003), youth are highly unlikely to rely on assistance from outside resources such as teachers, law representatives, and school officials when dealing with dating violence, but when help is sought adolescents do find that talking to others to be extremely helpful (Black \& Weisz, 2003; Henry \& Zeytinoglu, 2012, p. 29).

Table 1

2010 Baltimore City Demographics $(N=620,961)$

\begin{tabular}{lcc}
\hline Variables & Number & Percentage (\%) \\
\hline Race & $395,552.16$ & 63.7 \\
Black & $183,804.46$ & 29.6 \\
White & $41,604.39$ & 6.7 \\
Other & & \\
Gender & $292,472.63$ & 47.1 \\
Male & $328,488.37$ & 52.9 \\
Female & $40,983.43$ & 6.6 \\
Persons $\leq 5$ & $133,506.62$ & 21.5 \\
Persons $\leq 18$ & $72,652.44$ & 11.7 \\
Persons $\leq 65$ & $309,238.58$ & 49.8 \\
Home ownership & $\$ 39,386$ & N/A \\
Median household income & &
\end{tabular}

Source: U.S. Census Bureau. 
Table 2

2010 Statistics for Maryland

\begin{tabular}{lllllll}
\hline Area & & Population & Forcible rape & Violent crime & $\begin{array}{l}\text { Aggravated } \\
\text { assault }\end{array}$ & $\begin{array}{l}\text { Murder and non-negligent } \\
\text { manslaughter }\end{array}$ \\
\hline $\begin{array}{l}\text { Metropolitan } \\
\text { statistical area }\end{array}$ & $\begin{array}{l}\text { Area actually } \\
\text { reporting }\end{array}$ & $\begin{array}{l}5,465,306 \\
100 \%\end{array}$ & 1,179 & 30,535 & 18,082 & 417 \\
$\begin{array}{l}\text { Cities outside } \\
\text { metropolitan area }\end{array}$ & $\begin{array}{l}\text { Area actually } \\
\text { reporting }\end{array}$ & $\begin{array}{l}80,827 \\
100 \%\end{array}$ & 24 & 498 & 350 & 3 \\
$\begin{array}{l}\text { Non-metropolitan } \\
\text { counties }\end{array}$ & $\begin{array}{l}\text { Area actually } \\
\text { reporting }\end{array}$ & $\begin{array}{l}227,419 \\
100 \%\end{array}$ & 24 & 587 & 477 & 10 \\
State total & & $5,773,552$ & 1,227 & 31,620 & 18,909 & 430
\end{tabular}

Note. Rate per 100,000 21.3 547.7 327.5 7.4. Source: U.S. Department of Justice FBI.

Underreporting of IPV makes it hard to locate those in need, hard to get an accurate number of victims, hard to interpret data, and difficult to implement alternative preventive methods. Despite these challenges many women seek protection by calling the police, but all do not obtain protective orders (Logan et al., 2006, p. 178). This begs the question, how effective are protective orders? And what group is most protected: adults or adolescents? Various research studies have reported that between $23 \%$ and $70 \%$ of women experience a violation of a protective order (Carlson et al., 1999; Harrell \& Smith, 1996; Keilitz et al., 1997; McFarlene et al., 2004; Tjaden \& Thoennes, 2000; Logan et al., 2006, p. 191). These violation rates may be due to methodological differences between studies and jurisdictional differences, especially in the reporting rates for certain types of victimization-stalking, assault (sexual and physical), harassment, etc. ( Logan et al., 2006, p. 192).

As discussed the main preventive measure used is the criminal justice system. Even though this method is widely used, it is not utilized by all victims of IPV thus contributing to underreporting especially among minors. Studies have shown that women seek protection through the civil actions rather than criminal remedies. Civil actions can include divorce, legal separation, and protective orders/restraining orders (Logan et al., 2007, p. 245).

In the state of Maryland, domestic violence or intimate partner violence protective orders are available to both minors (18 and under) and adults. A protective order may last up to one year, with a possible six-month extension; a peace order may last up to six months. Persons may be eligible for protective order if they are a minor who has been the victim of abuse by:

(1) Someone you are married to/used to be married;

(2) Someone you had a sexual relationship with and lived for at least 90 days during a one-year period before you filed for the order;

(3) Someone related to you by blood, marriage, or adoption;

(4) Someone you have a child in common with;

(5) A parent, step-parent, child or step-child of you or the abuser can file for an order for a minor child or vulnerable adult (retrieved from www.wlcmd.org);

Victims under 18 are eligible for protection as well, if any one of the following persons file for a protective order on behalf of the victim:

(1) A person related to the child;

(2) An adult who lives with the child or vulnerable adult;

(3) The state attorney for the county where the child lives where the abuse took place;

(4) The Department of Social Services in the child lives or where the abuse took place (retrieved from 
http://www.wlcmd.org).

If a person is not eligible for a protective order, then a peace order may be filed. Peace orders, like protective orders, are civil orders ordered by a judge. The judge may order an individual to refrain from threatening or committing an act, end all contact, and/or stay away from the victim's home, place of employment or school. The judge may also order the parties to participate in joint or individual counseling and/or joint mediation. Peace orders may be issued for up to six months (retrieved from http://www.courts.state.md.com). In the state of Maryland, criminal and civil cases may be filed against an abusive individual.

Once filed an order of protection goes through several steps. Below are the steps in order:

(1) Step 1: Complete the correct petition: Petition for Protection (form CC/DCDV1) can be obtained from any circuit or District Court clerk or commissioner. A Petition for Peace Order (form DC/PO1) must be obtained from a District Court clerk or commissioner.

(2) Step 2: File the petition: During normal business hours, file the petition with a circuit or District Court clerk (District Court for peace orders). Once the petition is filed, you will then go to a courtroom to await a hearing; Step 2a: Interim Order: If courts are closed, District Court commissioners may issue Interim Peace and Protective Orders to last until a judge holds a temporary hearing. An interim order goes into effect once the respondent is served by a law enforcement officer.

(3) Step 3: Appear for a temporary hearing: When you appear before a judge, you will be required to answer questions under oath. If the judge finds reasonable grounds to believe that the respondent committed the acts alleged in the petition against you, (and in the case of a peace order, is likely to do so again) a temporary order is granted. The order goes into effect once a law enforcement officer serves the respondent and generally lasts for seven days unless extended by a judge.

(4) Step 4: Appear for a final hearing: A final hearing is usually scheduled within seven days after the order is served. At the hearing, both parties may present evidence. However, if the respondent does not attend, the judge may still grant a final order if at the trial the judge finds clear and convincing evidence that the respondent committed the alleged act against the petitioner, as defined under the law (and in the case of a peace order, is likely to do so again); or instead of a trial, the respondent consents to the entry of a final order.

Domestic violence cases are handled in either circuit court or district court. In district court there are no juries and the case is presided over and heard by a judge and criminal cases are handled under this division. In circuit court, civil cases along with major juvenile cases are handled. Given the overview of the legal process in obtaining protection against ones' abuser, one can see that this process can be exhaustive and frustrating for an adult, let alone, an adolescent.

A review of data for peace orders and protective orders was collected from the Maryland Judiciary website for the 2010 fiscal year. For the Baltimore City Circuit Court, the total number of juvenile peace orders was 103. Under District Court, the numbers of domestic violence cases filed and terminated are 4,265 and 4,136 irrespectively; and the numbers of peace order cases filed and terminated are 3,020 and 2,979. Peace orders and protective orders were also obtained from the District Court. From the total number of peace orders filed $(3,020), 1,431$ interim orders were granted, 2,470 temporary orders were granted, 894 peace orders were granted and six cases were appealed. And of the 4,265 filed domestic violence cases, 74 cases were transferred to Circuit Court, 2,199 interim orders were granted, 2,478 temporary orders were granted, 1,668 temporary orders were reissued, 1038 protective orders were granted, and six cases were appealed.

After reviewing the numbers of protective orders and peace orders filed and granted, it becomes apparent 
that there is no clear track between adults and minors in the Courts beyond peace orders being filed. In 2010, there was only 103 peace orders filed, however, the status of these peace orders are unknown. This gap of knowledge raised many questions regarding the effectiveness of orders (peace and protective) for minors exposed to intimate partner violence. If the main preventive measure used (police/court) is ineffective, adolescents exposed to IPV will continuously encounter health and psychological risks, which increases their chance of becoming vulnerable adults.

To better understand these filing numbers, contact was made to a representative at The Women's Law Center. A semi-structured qualitative phone interview was conducted in Fall of 2012 with an anonymous private attorney of the Women's Law Center. This method was used for several reasons. Because of its low cost and its efficiency in retrieving data information given the author's source's schedule, this method was optimal. Also, having semi-structured interview allowed me to ask the author's respondent a set of open-ended questions, which was sometimes accompanied by probes to help guide the discussion. Lastly, this method offered the author the most flexibility to incorporate new information based on the previous responses of the author's respondent making the tone "less-structured" allowing the author to gain more information.

The interview revealed that IPV cases are referred from both District and Circuit Court with the majority (60\%) stemming from Circuit Court. Most of the cases coming from this division are referred domestic violence cases which consist of a person who has filed an order of protection and the case has been appealed because of custody reasons. In addition, cases that are represented deal with partners who have a history of abuse or violence who have filed for custody. When asked about any visible trends or patterns observed in these cases, the source expressed two critical points which supported the literature. Firstly, most clients are in their early twenties who have been exposed to IPV in the past. Secondly, though victims of abuse have left their perpetrators, the issue of custody has led some clients to encountering their perpetrators on a continuous basis because of custody hearings. In concluding the author's interview, the author asked the source if there were any concerns they wished to express. In response, they remarked that the protective order services could be better which resembled the concerns expressed in literature measuring the effectiveness of orders. In addition, the author's source expressed exasperation on the "fickled" behavior in the filing of cases.

There is vast literature on preventive measures of intimate partner violence among married and unmarried cohabiting relationships. Recent analyses focusing on relationship trends have set their sights on unmarried cohabiting couples because of more people delaying marriage. According to the US Census Bureau, approximately 4.6 million households were classified as unmarried-partner (cohabiting) households, representing $4.2 \%$ of all households in the United States in 2003, which increased steadily from $2.9 \%$ in 1996 (Fields, 2003; Cole et al., 2007, p. 1114). Research has shown that there is a relationship between IPV and cohabiting. As a result, this has led to changes in legal protection offered for IPV. For example, all 50 states have now authorized civil protective orders that allow petitioners to file on behalf of themselves (Eigenberg etal., 2003; Cole et al., 2007, p. 1115).

After reviewing the responses from the legal source, more attention is needed toward juvenile/adolescent IPV cases. The filing of peace and protective orders are time sensitive, and a request for an order may not be granted if the victim does not file for a peace or protective order request directly after the incident. This may prove to be challenging especially for protective orders because the adult has to file on behalf of the child if there is no common child between the abused and abuser, and there is no cohabitation between the abused and abuser. In addition, one has 30 days to file a petition of order from the date of incident. This may pose a 
problem for some teenage victims especially if they feel embarrassed or ashamed to inform a parent or guardian. If these emotions are present, action taken against the abuser will not occur immediately thus increasing the risk of repeated abuse. This leads one to examine other alternative methods of prevention for this target population.

\section{Community Services}

Community-based services for women and children affected by domestic violence have evolved substantially since their beginnings in the 1970s and 1980s (Carter et al.,1999, p. 7). Community-based domestic violence services is one of the leading facilities assisting victims of domestic violence by providing comprehensive services free of charge to help rebuild their lives. This location was selected because of its Teen Dating Violence Prevention Initiative in 1997, a community based program geared towards teaching adolescents and young adults about healthy relationships, and the author was interested to see whether or not these services are being utilized.

Located in Northeast Baltimore, the shelter provides the following: shelter, counseling for adults, teens, and children, legal advocacy, abusers intervention, professional training, and community outreach services. Direct contact was made to the facility during the months of October and November to obtain primary and secondary data. Secondary data was analyzed to obtain basic demographic information, services/programs utilized, employment and income status, and educational history of participants. Table 3 presents the basic descriptive statistics for the sample during the 2010 fiscal year.

As indicated most of the participants are single African-American women between the ages of 20-39. Though not indicated, all participants except for 9 indicated that they had children ranging from 1-8. From the sample, the values were obtained: 68 participants have one child; 75 participants have two children; 50 participants have three children; 28 participants have four children; 12 participants have five children; six participants have six children; one participant has seven children; and one participant has eight children. Most participants did not indicate their level of education at $54 \%$, followed by $14 \%$ receiving some college education, and then $13 \%$ receiving a high school diploma. One plausible explanation could be that this was not required information for using specific programs, i.e., Adult Counseling or Client Services or when clients sought assistance.

Employment and source of income for participants for the fiscal year of 2010 is indicated in Table 4 . The majority of participants did not indicate their employment status for this fiscal year which left $49 \%$ of the population accounted for under this variable. One plausible explanation could be that this was not required for using specific programs, i.e., adult counseling or client services. Another explanation could be personal reasons or fear of stigma. Similar to underreporting, victims are sometimes reluctant to reveal information because of embarrassment or fear of being stigmatized by society. Even though the sample size is 438 at least 104 participants received more than one source income during the 2010 fiscal year. As indicated, 51\% of participants did not indicate their employment status, followed by $26 \%$ who are unemployed and received no benefits, and $10 \%$ who are employed full-time. Source of income varied across 15 variables. From the sample size $34 \%$ did not identify their source of income and $11 \%$ indicating they had no source of income. Interestingly, fewer than $3 \%$ of the sample received child support or alimony despite $98 \%$ of the population having children. Most of the participants (86) indicated that their source of income is provided by food stamps at $16 \%$ followed by 80 participants receiving a salary at $15 \%$. 
Table 3

Descriptive Statistics FY2010

\begin{tabular}{|c|c|c|}
\hline Variables & $N$ & Percentage (\%) \\
\hline \multicolumn{3}{|l|}{ Gender } \\
\hline Female & 432 & 99 \\
\hline \multirow[t]{2}{*}{ Male } & 6 & 1 \\
\hline & 438 & \\
\hline \multicolumn{3}{|l|}{$\overline{\text { Age }}$} \\
\hline 0 (age not indicated) & 26 & \\
\hline $1-19$ & 1 & \\
\hline $20-39$ & 295 & \\
\hline $31-59$ & 110 & \\
\hline \multirow[t]{2}{*}{$60-59$} & 6 & \\
\hline & 438 & \\
\hline \multicolumn{3}{|l|}{ Race } \\
\hline African-American & 222 & 51 \\
\hline Asian & 2 & 0.45 \\
\hline Bi-Racial & 5 & 1 \\
\hline Caucasian & 55 & 13 \\
\hline Hawaiian or Pacific Islander & 1 & 0.23 \\
\hline Hispanic & 14 & 3 \\
\hline Multi-Racial & 2 & 0.45 \\
\hline Other & 10 & 2 \\
\hline \multirow[t]{2}{*}{ Race Not Indicated } & 127 & 29 \\
\hline & 438 & \\
\hline \multicolumn{3}{|l|}{ Marital status } \\
\hline Divorced & 19 & 4 \\
\hline Domestic Partner & 6 & 1 \\
\hline Married & 80 & 18 \\
\hline Separated & 28 & 6 \\
\hline Single & 183 & 42 \\
\hline Status Not Indicated & 121 & 28 \\
\hline \multirow[t]{2}{*}{ Widowed } & 1 & 0.23 \\
\hline & 438 & \\
\hline \multicolumn{3}{|l|}{ Education level } \\
\hline Advanced degree & 3 & 1 \\
\hline Associate's degree & 4 & 1 \\
\hline Bachelor's degree & 12 & 3 \\
\hline Education not indicated & 235 & 54 \\
\hline GED & 12 & 3 \\
\hline High school diploma & 56 & 13 \\
\hline Less than high schoo & 8 & 2 \\
\hline No school & 1 & 0.23 \\
\hline Some college & 60 & 14 \\
\hline Some high school & 36 & 8 \\
\hline Student & 3 & 1 \\
\hline Unknown & 5 & 1 \\
\hline \multirow[t]{2}{*}{ Vocational/technical certificate/degree } & 3 & 1 \\
\hline & 438 & \\
\hline
\end{tabular}


Table 4

Employment and Source of Income Statistics FY2010

\begin{tabular}{|c|c|}
\hline & $N$ \\
\hline \multicolumn{2}{|l|}{ Employment status } \\
\hline Employed full-time & 46 \\
\hline Employed part-time & 20 \\
\hline Employed seasonal & 2 \\
\hline Employment not indicated & 222 \\
\hline In training program & 1 \\
\hline Never worked & 5 \\
\hline Retired & 2 \\
\hline Self-employed & 2 \\
\hline Unemployed benefits & 2 \\
\hline \multirow[t]{2}{*}{ Unemployed no benefits } & 115 \\
\hline & 439 \\
\hline \multicolumn{2}{|l|}{ Source of income } \\
\hline Alimony & 1 \\
\hline Child support & 12 \\
\hline Food stamps & 86 \\
\hline Medical assistance & 20 \\
\hline None & 59 \\
\hline Other & 5 \\
\hline Retirement/pension (not social security) & 1 \\
\hline Salary & 80 \\
\hline Social security & 7 \\
\hline Source not indicated & 184 \\
\hline SSDI-disability & 16 \\
\hline SSI & 18 \\
\hline TCA-temp. cash assistance & 41 \\
\hline TDAP-temp. disability assistance program & 2 \\
\hline TEHMA & 4 \\
\hline \multirow[t]{2}{*}{ Unemployment compensation } & 7 \\
\hline & 542 \\
\hline
\end{tabular}

The services available to participants at the House of Ruth were categorized into 14 programs (Table 5). Even though the sample size is 438 , participants were able to utilize more than service during their time at the House of Ruth which resulted with a total of 1,190. Of the services used, 406 participants used Client Services, followed by the Contact Center and Outreach at 295 participants, and 172 participants in Adult Counseling. Client Services is a fully functioning help center that is staffed with trained counselors and volunteers that assists victims with the necessary services to rebuild their lives and to meet each individual's needs. Overseeing this program is a service coordinator who can connect victims to outside services like housing, job training, or child care. The Contact Center and Outreach program seeks to both provide services and inform community members about domestic violence and the shelter. Workshops, trainings, and short-term groups are available at substance abuse treatment programs, parent support centers, and medical clinics are also provided under this program. The domestic violence shelter offers private and group adult counseling on the issue of domestic violence by trained professionals. This table indicates that the legal program, legal abuser, and child and family counseling programs are not used adequately despite $98 \%$ of the population having children. 
Table 5

Programs Used

\begin{tabular}{lrc}
\hline Statistics FY 2010 & \multicolumn{2}{c}{} \\
\hline Program & 172 & Percentage (\%) \\
\hline Adult counseling & 3 & 14.45 \\
Child and family counseling & 406 & 0.25 \\
Client services & 295 & 34.12 \\
Contact center and outreach & 3 & 24.79 \\
DV women & 12 & 0.25 \\
General abuser & 15 & 1.01 \\
Intake & 85 & 1.26 \\
Legal & 1 & 7.14 \\
Legal abuser & 57 & 0.08 \\
Police lethality project & 25 & 4.79 \\
Safe homes & 103 & 2.10 \\
Shelter & 1 & 8.66 \\
Training and outreach & 12 & 0.08 \\
Victim contact & 1,190 & 1.01 \\
\end{tabular}

Upon retrieving data from the shelter, a semi-structured interview was scheduled with the Director of Client Services. Below are the asked questions in the areas which were of concern:

(1) The goal of this study is to examine the preventive measures that are around to protect abuse victims. Do you feel that the facility has done that? If so, what services?

(2) What services does the shelter provide at this present location? In examining the data, "Client Services" were largely used, followed by "Contact Center and Outreach". Could you please explain what each service provides?

(3) What services does the shelter provide for minors (18 and under)? Is there such a program?

(4) What is being done, from the position of the organization to assist kids that have been exposed to violence?

(5) Is there a distinction of services that's dependent on the severity of abuse? For example, if a client does not willingly use a service he/she is enrolled in are they referred to other programs by a staff member?

(6) In terms of client outcomes: Are follow-up services provided for clients? If so, under what circumstances? Where if utilized, are these services effective?

(7) If additional funding was provided for this location and for this facility (in general), what need would be met?

Because IPV is an issue that affects individuals within the home and outside the home, the domestic violence sheter has participated in the community organizations and school and youth groups to bring awareness about healthy relationships and dating violence. Since most of their prevention programs are funded, it limits their effectiveness if their services are not hired by members/organizations in the community. For example, the "teen prevention" services programs were cut due to the "inability of the school system to make this part of their curriculum".

Despite this shortfall, the domestic violence shelter continues to be influential in providing members direct service which is tailored to meet the needs of victims as illustrated by the Client Service Program which houses 
service coordination. Under this program, the individual is assessed and then services are tailored to meet the specific needs of the individual thus it is not "one size fits all" design. This program offers individual with various resources like housing, legal assistance, counseling, mental health and substance abuse assistance, and work programs to meet their individual needs. This program was largely used by participants as indicated in Table 5 .

The shelter provides legal services in their legal clinics particularly custody assistance, shelter services, counseling and outreach, advocacy and training, abuser's intervention services, and volunteer programs. From Table 5, we can see that only $7 \%$ of participants utilize this program and under $1 \%$ utilizing the Legal Abuser Program. Even though this program is under-utilized, the facility has trained counselors who administer 20-question lethality assessment questionnaires to victims to measure their exposure to abuse while educating victims on what signs to look out for. These tools are done in counseling services, however, it is beneficial to a mainly adult population.

As indicated in Table 3, the center's participants are above minor age (18 and up). As a result, parents are responsible for their children and nothing can be done without the consent of the parent. Health services like immunizations, home visits, or assistance for children with special needs are provided for victims and their children who work in conjunction with Johns Hopkins Hospital. In addition to Johns Hopkins Hospital, the University of Maryland sponsors "Mom and Babies Breakfast" for victims who have infants and toddlers once a week. Even though most of the services are granted once the consent of the parents is granted, emancipated minors or in some cases legal guardians could grant consent so services could be administered. Services are available for victims and their children who may fall under the age of eighteen. For example, family therapy group day that is funded by the Kennedy Krieger grant which treats families exposed to a lot of trauma to a group dinner. A service coordinator is assigned to the group(s) in which both the parents and children are able to receive age appropriate counseling at the same time but in different rooms.

\section{Solutions}

This paper has revealed the need for additional prevention alternatives. This focus will continue to be critical as more studies show the similarity in domestic violence statistics between high-school and college students. According to ACADV (the Alabama Coalition Against Domestic Violence), one in five college females will experience some form of violence while in a dating relationship and about one in three high school students have been or will be involved in an abusive relationship (retrieved from http://www.voices.yahoo.com). Though studies have indicated the alarming rates of dating violence among adolescents, there is little being done that specifically targets this population.

As illustrated, community based programs have offered assistance to abuse victims but as indicated in Table 3 these services are utilized by victims between the ages of 20-39, and not those between the ages of 13-19. In addition, data from this study also illustrated that among the services used legal services was utilized at a low rate of $7 \%$ during the 2010 fiscal year. Each wave has dramatically showed the absence of abused adolescent victims utilizing these services/programs. Measures to minimize the rate of teen violence have been largely done at the state level, however, better measures on the local level needs to be done. In 2010, only 103 juvenile peace orders were documented out of 133, 506 persons under the age of 18 (see Table 1).

Maryland allows the state of Board of Education to encourage county boards to incorporate age appropriate lessons on dating violence in the county board's health education curriculum (retrieved from http://www.ncsl.org). Though this need has been supported, schools are lacking programs and counselors to 
deal with this type of violence. A study out of Ball State University found that most schools do not consider adolescent dating violence a high-priority issue, with $81.3 \%$ of high school counselors surveyed reporting that their schools do not have a protocol or procedure in place for responding to incidents of such violence (Huff Post Education).

Studies have shown that exposure to teen dating violence are precursors for more serious violence like physical assaults. If no intervention is in place then unhealthy behaviors are deemed "normal" and "healthy", further perpetuating the cycle thus contributing to re-abuse or recidivism when the child becomes an adult. Also, if arrests reduce domestic violence for some men because they fear the consequence of continuing their abuse, then women need to understand the difference between temporary orders and permanent orders (Carlson et al., 1999, p. 209). These two areas would not be met if there is no dissemination of knowledge during one's adolescent years.

This study revealed that services of the courts and community based programs are used mainly by victims with children. The exclusion of the adolescent population in filing for protective or peace orders makes it difficult to address the specific needs adolescents face in violent relationships. This lack of inclusion only compounds the negative effects associated with physical dating violence among teens. It is the author's hope to provide services tailored specifically for adolescent victims which can be implemented into high schools by doing the following:

(1) Increasing access to protective order and peace order paperwork at school;

(2) Improving the location of juveniles who have filed and received peace and protective orders from the adult population;

(3) Improving community based programs legal aid services and awareness.

Studies have shown that younger victims of abuse are less inclined to seek help. To aid in this area, one's access to protective order and peace order paperwork should come to victims and not the other way around. Adolescent victims are at greater risk than adults because of their limited access to resources. As a result, each school should be equipped with these forms especially if the school has a counselor, nurse's office, or an official school police on site. If equipped with one of these representatives, they could have the legal authority to initiate the process as seen with child abuse cases. If done correctly, this would improve the filing and maintenance of juvenile domestic violence cases. As illustrated earlier, after a juvenile filed, there was no knowing whether or not the 103 juvenile victims were successful in having their award granted.

The client has to be willing to utilize the community services that are offered at domestic violence shelters, or healthcare community based programs where recommendations are made. At the House of Ruth, participants utilized least the legal services which provided victims of abuse needed legal tools on what steps to take ensure their family's safety. Proper dissemination of legal literature should be made available in all areas of the community: schools, churches, neighborhood YMCA, healthcare facilities, and police stations. By doing this parents, not just adolescents will open up about domestic violence. Research has shown that adults who have been exposed to domestic violence were victims of violence before. The involvement of parents along with community initiatives would help curb this trend.

\section{Conclusion}

This paper sought to ascertain the options available for minors exposed to IPV. The most widely used measure against IPV has been the court system. To make protective orders more accessible and enforceable, the 
1994 VAWA (Violence Against Women Act) provided no filing fees or service costs for protection orders and a full faith and credit provision to ensure law enforcement protection in any state, regardless of the state where the protective order was issued (Gist et al., 2001, p. 638). Given this legislation, the body of knowledge for minors filing for protective or peace orders is still limited.

The qualitative and quantitative portions of this study have raised few key points. As supported in previous studies on the effectiveness of protective orders or peace orders, more follow-up studies need to be done on victims who have taken out temporary or permanent orders, however because juvenile filers are fewer in number, emphasis should be placed on locating this population and improving the filing process for juveniles. In distinguishing the composition of "filers" one could ascertain whether or not custody disputes influence one to reduce the length of these orders. Also, more research needs to be done in ascertaining the amount of minors who have been exposed to IPV or dating violence. Because underreporting is higher among this group, it is important to actively bring schools, community organizations, and health and mental care facilities on board like they do with "cyber bullying" or more popular violence affecting the youth. Lastly, better organization and feasibility needs to take place in acquiring a protective or peace order. One key thing that was very important was the usage of legal services. During the 2010 fiscal year, legal services was used $7 \%$ ( 85 participants) of the fiscal year compared to other popular programs like client services which was used at $34 \%$ by 406 participants.

The services provided at domestic violence shelters are essential in keeping victims of IPV not only safe but knowledgeable of their rights. Of all the services provided, Client Services is the most used and it is understood. Many studies have supported the notion that dependency prolongs abuse and this has become embedded into the mission of this shelter. The underuse of legal services has raised great concern in this study because this program deals with protective orders, legal assistance, and custody issues. If this segment is underused then what does it say about the numbers produced by local District and Circuit courts? One cannot simply examine secondary data to obtain an accurate sense of what is being done to curb the exposure of IPV to minors. This study has shown that better statistical measures are needed to locate minors who have been exposed to IPV in the court system and the communities before steps are taken to measure the effectiveness of protective/peace orders.

\section{References}

Black, B. M., \& Weisz, A. N. (2003). Dating violence: Help-seeing behaviors of african american middle schoolers. Violence Against Women, 9, 187-206.

Brownridge, D. (2002). Cultural variation in male partner violence against women. Violence Against Women, 8, 87-115.

Carlson, M., Harris, S., \& Holden, G. (1999). Protective orders and domestic violence: Risk factors for re-abuse. Journal of Family Violence, 14(2), 205-226.

Carter, L., Weithorn, L., \& Behram, R. (1999). Domestic violence and children: Analysis and recommendations. The Future of Children, 9(3) (Domestic Violence and Children), 4-20.

CDC. (2003). Costs of intimate partner violence against women in the United States. Atlanta, G.A.: US Department of Health and Human Services. Retrieved from http://www.cdc.gov/ncipc/pub-res/ipv_cost/IPVBook-Final-Feb18.pdf

CDC. (2003). From physical dating violence among high school students-United States 2003. MMWR Weekly, May 19, 2006. (Vol. 55, No. 19, pp. 532-535). Retrieved from www.cdc.gov/ViolencePrevention/intimatepartnerviolence/teen_dating _ violence.html

Center for Disease Control and Prevention (Factsheet). (2006). Retrieved from http://www.cdc.gov/violenceprevention/pdf/IPV_factsheet-a.pdf

Center for Disease Control and Prevention (Factsheet). (2012). Retrieved from http://www.cdc.gov/violenceprevention/pdf/IPV_factsheet-a.pdf 
Eigenberg, H., McGuffee, K., Berry, P., \& Hall, W. (2003). Protective order legislation: Trends in state statutes. Journal of Criminal Justice, 31, 411-422.

Fields, J. (2003). America's families and living arrangements: 2003 (Current Population Reports, pp. 250-553). Washington, D.C.: U.S. Census Bureau.

Gist, J., McFarlene, J., Malecha, A., Fredland N., Schultz. P., \& Wilson, P. (2001). Women in danger: Intimate partner violence experienced by women who qualify and do not qualify for a protective order. Behavioral Sciences and the Law, 19, 637-647.

Halpern, C. T., Oslak, S. G., Young, M. L., Martin, S. L., \& Kupper, L. L. (2001). Partner violence among adolescents in opposite-sex romantic relationships: Findings from the national longitudinal study of adolescent health. American Journal of Public Health, 91, 1679-1685.

Hanson, K., \& Wallace-Capretta, S. (2000-2006). Predicting recidivism among male batterers. Department of the Solicitor General Canada. Retrieved from http://www.publicsafety.gc.ca/res/cor/rep/2000-06-pramb-eng.aspx

Harrell, A., \& Smith, B. (1996). Effects of restraining orders on domestic violence victims. Do arrests and restraining orders work? (pp. 212-242). Thousand Oaks, C.A.: Sage.

Harrell, A., Smith, B., \& Newmark, L. (1993). Court processing and the effects of restraining orders for domestic violence victims Washington, D.C.: The Urban Institute.

Henry, R. R., \& Zeytinoglu, S. (2012). African Americans and teen dating violence. The American Journal of Family Therapy, 20, 20-32.

Huff Post Education. (2012). Teen dating violence: U.S. high schools unequipped to handle the issue, study shows. Retrieved from www.huffingtonpost.com/2012/07/24/study

Jiwani, Y. (2000). The 1999 General social survey on spousal violence: An analysis. Canadian Woman Studies/Les cahiers de la Femme, 20, 34-41.

Johnson, M. (2005). Domestic violence: It's not about gender: Or is it? Journal of Marriage and Family, 67(5), 1126-1130.

Keilitz, S., Hannaford, P., \& Efkeman, H. (1997). Civil protection orders: The benefits and limitations for victims of domestic violence (Publication No. R-201). National Center for State Courts Research Report. Wiliamsburg, Va.

Logan, T. K., \& Walker, R. (2009). Civil protective order outcomes: Violations and perceptions of effectiveness. Journal of Interpersonal Violence, 24(4), 675-692.

Logan, T. K., Cole, J., Shannon, L., \& Walker, R. (2007). Relationship characteristics and protective orders among a diverse sample of women. Journal of Family Violence, 22, 237-246.

Logan, T. K., Shannon, L., Walker, R., \& Faragher, T. M. (2006). Protective orders: Questions and conundrums. Trauma, Violence, and Abuse, 7(3), 175-205.

MacMillan, R., \& Rosemary, G. (1999). When she brings home the bacon: Labor-force participation and the risk of spousal violence against women. Journal of Marriage and the Family, 61, 947-958.

McFarlene, J., Malecha, A., Gist, J., Watson, K., Batten, E., Hall, I., et al. (2004). Protection orders and intimate partner violence: An 18-month study of 150 Black, Hispanic, and White women. American Journal of Public Health, 94(4), 613-618.

Marshall, L. (1992). Development of the severity of violence against women scales. Journal of Family Violence, 7, 103-121.

Public Safety Canada. (2004). Retrieved from http://www.publicsafety.gc.ca/res/cor/rep/2004-04-rsk-abs-eng.aspx

Remler, D., \& Van Ryzin, G. (2011). Research methods in practice: Strategies for description and causation. Sage Publications.

Reynolds, F., \& Sheperd, C. Y. (2011). Women's accounts of intimate partner violence during adolescence and subsequent recovery processes: An interpretative phenomenological analysis. Psychology and Psychotherapy: Theory, Research, and Practice, 84, 314-334.

Sanday, R. (1981). The socio-cultural context of rape: A cross-cultural study. Journal of Social Issues, 37, 5-27.

Sleutal, M. (1998). Women's experiences of abuse: A review of qualitative research. Issues in Mental Health Nursing, 19(6), 525-539.

Strauss, M. (2007). Conflict tactics scales (pp. 190-197). Encyclopedia of Domestic Violence.

Tjaden, P., \& Thoennes, N. (2000). Full report of the prevalence, incidence, and consequences of violence against women (NCJ 183781). Washington, D.C.: U.S. Department of Justice, Office of Justice Programs, National Institute of Justice. 